\title{
Lista de Revisores de 2020
}

O Corpo Editorial da Revista Portuguesa de Medicina Geral e Familiar realça o papel dos revisores no sucesso da Revista, particularmente a sua crítica construtiva aos artigos submetidos à revisão por pares.

Terminado um ano, fustigado por inúmeros desafios provocados pela pandemia, agradecemos aos revisores o seu profissionalismo, o qual permitiu assegurar o processo editorial durante o ano de 2020.

\begin{tabular}{|c|c|}
\hline NOME & AFILIAÇÃO PROFISSIONAL \\
\hline Abel Abejas & Medicina Geral e Familiar \\
\hline Afonso Sousa & Medicina Geral e Familiar \\
\hline Ana Brochado & Medicina Geral e Familiar \\
\hline Ana Cebolais & Medicina Geral e Familiar \\
\hline Ana de Oliveira & Medicina Geral e Familiar \\
\hline Ana Filipa Vilaça & Medicina Geral e Familiar \\
\hline Ana Luísa Duarte & Medicina Geral e Familiar \\
\hline Ana Magalhães & Medicina Geral e Familiar \\
\hline Ana Margarida Cruz & Medicina Geral e Familiar \\
\hline Ana Pinheiro & Medicina Geral e Familiar \\
\hline Ana Rita Costa & Medicina Geral e Familiar \\
\hline Ana Rita Cerqueira & Medicina Geral e Familiar \\
\hline Ana Rita Luz & Medicina Geral e Familiar \\
\hline Ana Rodrigues & Medicina Geral e Familiar \\
\hline André Coelho & Medicina Geral e Familiar \\
\hline André Ramalho & Medicina Geral e Familiar \\
\hline Andreia Silva e Sousa & Medicina Geral e Familiar \\
\hline António Cruz-Ferreira & Medicina Geral e Familiar \\
\hline Bruno Maia & Medicina Geral e Familiar \\
\hline Bruno Valentim & Medicina Geral e Familiar \\
\hline Carlos Cardoso & Medicina Geral e Familiar \\
\hline Cátia Lírio & Medicina Geral e Familiar \\
\hline Célia Mata & Medicina Geral e Familiar \\
\hline Cláudia Vicente & Medicina Geral e Familiar \\
\hline Cristina Gonçalves & Medicina Geral e Familiar \\
\hline Deolinda Chaves Beça & Medicina Geral e Familiar \\
\hline Diana Brigas & Medicina Geral e Familiar \\
\hline Diana Rocha & Medicina Geral e Familiar \\
\hline Dilermando Sobral & Medicina Geral e Familiar \\
\hline Elmano Margato & Medicina Geral e Familiar \\
\hline Eurico Silva & Medicina Geral e Familiar \\
\hline Filipa Manuel & Medicina Geral e Familiar \\
\hline Filipa Guedes & Medicina Geral e Familiar \\
\hline Filipe Alves & Medicina Geral e Familiar \\
\hline Filipe Almeida & Medicina Geral e Familiar \\
\hline Hugo Rocha & Medicina Geral e Familiar \\
\hline Inês Teixeira & Medicina Geral e Familiar \\
\hline Irene Trindade & Medicina Geral e Familiar \\
\hline Isabel Fragoso & Medicina Geral e Familiar \\
\hline Isabel Tomás & Medicina Geral e Familiar \\
\hline Ivo Reis & Medicina Geral e Familiar \\
\hline
\end{tabular}

\begin{tabular}{|c|c|}
\hline NOME & AFILIAÇÃO PROFISSIONAL \\
\hline Ivone Martins & Medicina Geral e Familiar \\
\hline Joana Cabete & Medicina Geral e Familiar \\
\hline Joana Carneiro & Medicina Geral e Familiar \\
\hline Joana Ferreira Alves & Medicina Geral e Familiar \\
\hline Joana Monteiro & Medicina Geral e Familiar \\
\hline Joana Oliveira & Medicina Geral e Familiar \\
\hline Joana Ramalho & Medicina Geral e Familiar \\
\hline Joana Reis & Medicina Geral e Familiar \\
\hline Joana Saldanha & Medicina Geral e Familiar \\
\hline João Pedro Antunes & Medicina Geral e Familiar \\
\hline José Augusto Simões & Medicina Geral e Familiar \\
\hline José Maria Silva Henriques & Medicina Geral e Familiar \\
\hline José Mendes & Medicina Geral e Familiar \\
\hline José Santos & Medicina Geral e Familiar \\
\hline Leonor Grijo & Medicina Geral e Familiar \\
\hline Luís Monteiro & Medicina Geral e Familiar \\
\hline Luísa João & Medicina Geral e Familiar \\
\hline Luísa Pires & Medicina Geral e Familiar \\
\hline Madalena Sales Luís & Medicina Geral e Familiar \\
\hline Márcia Sá & Medicina Geral e Familiar \\
\hline Mariana Rio & Medicina Geral e Familiar \\
\hline Maria Adriana Rangel & Medicina Geral e Familiar \\
\hline Maria Amélia Cunha & Medicina Geral e Familiar \\
\hline Maria da Graça Cardoso & Medicina Geral e Familiar \\
\hline Maria do Carmo Gonçalves & Medicina Geral e Familiar \\
\hline Maria João Araújo & Medicina Geral e Familiar \\
\hline Maria Luísa Carvalho & Medicina Geral e Familiar \\
\hline Maria Malvar Ferreira & Medicina Geral e Familiar \\
\hline Maria Manuel Marques & Medicina Geral e Familiar \\
\hline Marisa Rodrigues & Medicina Geral e Familiar \\
\hline Marta Magalhães & Medicina Geral e Familiar \\
\hline Marta Nazha & Medicina Geral e Familiar \\
\hline Marta Raquel Matos & Medicina Geral e Familiar \\
\hline Martino Gliozzi & Medicina Geral e Familiar \\
\hline Miguel Ferreira & Medicina Geral e Familiar \\
\hline Miguel Monte & Medicina Geral e Familiar \\
\hline Natália Teles & Medicina Geral e Familiar \\
\hline Nelson de Brito & Medicina Geral e Familiar \\
\hline Nuno Florêncio & Medicina Geral e Familiar \\
\hline Paula Aldomiro & Medicina Geral e Familiar \\
\hline Paula Miranda & Medicina Geral e Familiar \\
\hline
\end{tabular}


NOME

Paulo Baptista Coelho

Pedro Campos

Pedro Miranda

Priscila Pereira

Rita Marecos

Rita Meireles Pedro

Rita Oliveira

Roberto Rodrigues

Rosa Costa

Rute Carvalho

Sara Cunha

Sara Madeira

\section{AFILIAÇÃO PROFISSIONAL NOME}

Medicina Geral e Familiar Medicina Geral e Familiar Medicina Geral e Familiar Medicina Geral e Familiar Medicina Geral e Familiar Medicina Geral e Familiar Medicina Geral e Familiar Medicina Geral e Familiar Medicina Geral e Familiar Medicina Geral e Familiar Medicina Geral e Familiar Medicina Geral e Familiar
Sara Pinho

Sénia Marisa Guerreiro

Sibila Amaral

Sofia Oliveira

Susana Cadinha

Susana Silva Pinto

Taiane Abreu

Tatiana Peralta

Teresa Velosa

Tiago Baptista

Vera Costa

Victor Ramos
AFILIAÇÃO PROFISSIONAL

Medicina Geral e Familiar Medicina Geral e Familiar Medicina Geral e Familiar Medicina Geral e Familiar Medicina Geral e Familiar Medicina Geral e Familiar Medicina Geral e Familiar Medicina Geral e Familiar Medicina Geral e Familiar Medicina Geral e Familiar Medicina Geral e Familiar Medicina Geral e Familiar 